\title{
A quantitative evaluation of sciatic nerve stiffness after compression by shear wave elastography in diabetic rats
}

\author{
Diancheng Li, Jiaan Zhu, Fang Liu, Bing Li, Feifei Liu, Wenxue Li \\ Department of Ultrasound, Peking University People's Hospital, Beijing, China \\ Contributions: (I) Conception and design: J Zhu, F Liu; (II) Administrative support: J Zhu, F Liu; (III) Provision of study materials: D Li, B Li; (IV) \\ Collection and assembly of data: D Li, B Li, F Liu; (V) Data analysis and interpretation: D Li, F Liu, W Li; (VI) Manuscript writing: All authors; (VII) \\ Final approval of manuscript: All authors. \\ Correspondence to: Jiaan Zhu; Fang Liu. Department of Ultrasound, Peking University People's Hospital, No. 11 Xizhimen South Street, Beijing, \\ China. Email: zhujiaan@pkuph.edu.cn; liufangyt@163.com.
}

\begin{abstract}
Background: Our study investigates the feasibility of using quantitative evaluation for nerve entrapment visualization by shear wave elastography (SWE) in diabetic rats.

Methods: A total of 24 male Sprague-Dawley (SD) rats were included in this study. Before injection of streptozotocin (STZ), the experimental groups were assigned as the diabetic nerve compression (DNC) group (DNC, $n=18)$ and the control group $(\mathrm{CON}, \mathrm{n}=6)$. The DNC model was created by wrapping a silicone tube around the nerve, and then the DNC group was divided into the DNC 2-week (DNC2W, $\mathrm{n}=6$ ), 4-week (DNC4W, $\mathrm{n}=6$ ), and 8-week (DNC8W, n=6) groups according to the different duration time of sciatic nerve compression. The nerve stiffness was detected by SWE. Meanwhile, motor nerve conduction velocity (MNCV) was detected. These 2 indicators and histology of sciatic nerves were compared across the different groups.

Results: The stiffness of the nerve depicted by SWE at the compression site increased markedly along with the duration time of compression $(\mathrm{P}<0.01)$. The MNCV decreased along with the duration time of nerve compression $(\mathrm{P}<0.05)$. The nerve stiffness depicted by SWE was negatively correlated with MNCV $(\mathrm{r}=-0.926$; $\mathrm{P}<0.01)$. Myelinated fiber density significantly decreased as the duration time of nerve compression increased $(\mathrm{P}<0.01)$. Some differences were found between DNC4W and DNC8W groups, and CON and DNC2W groups $(\mathrm{P}<0.05)$ in average axon diameter, myelin sheath thickness, and $\mathrm{g}$ ratio.

Conclusions: The increased values of SWE, along with the increased duration of nerve compression, could reflect the severity of nerve entrapment in diabetic rats. Therefore, SWE may be used as a noninvasive and effective method to quantitatively evaluate the severity of diabetic nerve entrapment.
\end{abstract}

Keywords: Diabetic neuropathy; shear wave elastography (SWE); nerve compression; sciatic nerve

Submitted Dec 20, 2019. Accepted for publication May 09, 2020.

doi: $10.21037 /$ atm-19-4534

View this article at: http://dx.doi.org/10.21037/atm-19-4534

\section{Introduction}

Diabetic peripheral neuropathy (DPN) is one of the most common complications of diabetes mellitus (DM). DPN presents a variety of issues, which include sensory and motor dysfunctions, resulting in substantial morbidity, disability, and mortality, such as reduplicative lower extremity infections, ulcers, and amputation (1). It is reported that up to $50 \%$ of diabetic patients suffer from painful symptoms of diabetic neuropathy, resulting in a decline in the quality of life and being a burden to the economy $(2,3)$.

Chronic nerve entrapment is a clinical disease occurring more commonly in diabetic neuropathy patients than in nondiabetic patients (4). It is particularly apparent with carpal tunnel syndrome (CTS), as about $20-30 \%$ of diabetic neuropathy patients have accompanying CTS 
$(5,6)$. On the basis of the double-crush concept, which states that nerves subjected to metabolic or mechanical compressions at one site are more prone to experience compression at another site, DM patients are more susceptible to nerve entrapment (7). Dellon reported the first application of decompression surgery in the treatment of peripheral compression nerve in diabetics (8). Surgical nerve decompression may be a useful method for alleviating neuropathic symptoms and reducing the incidence rate of correlative complications (9). Nevertheless, the decompression surgery for CTS may be required at 4 times higher frequency in diabetic patients than in the average population (10). Therefore, multiple quantitative evaluations of diabetic nerve entrapments are inevitable.

Electrophysiological exams have been customarily used to evaluate diabetic neuropathy or CTS in diabetes before decompression surgery $(11,12)$. However, it is time-consuming and painful for patients. Shear wave elastography (SWE) is purportedly a noninvasive technique that can reflect the elasticity of tissue by the propagation of shear waves. The velocity of the shear wave in the tissue increases with the rise of tissue stiffness (13). Some studies, in which SWE was used to evaluate the diabetic neuropathy or CTS, have reported that the increase in stiffness of the nerve can be reflected by SWE (14-16). Nevertheless, there have been no pathological results obtained to verify the accuracy of nerve stiffness measured by SWE in diabetic nerve compression. Furthermore, whether the higher velocity of the shear wave can help to grade the severity of nerve entrapment in diabetes is also unclear.

Given these deficiencies in research, this study aimed to verify the effectiveness of SWE in the evaluation of nerve entrapment of diabetic rats and to investigate further the relationship between nerve stiffness depicted by SWE and the pathological and functional changes of the sciatic nerve.

We present the following article in accordance with the ARRIVE reporting checklist (available at http://dx.doi. org/10.21037/atm-19-4534).

\section{Methods}

\section{Animals and groups}

A total of 24 male Sprague-Dawley (SD) rats (Beijing Vital River Laboratory Animal Technologies Co. Ltd, China) aged 8 weeks and weighing 250-300 g were used in this study; 6 normal SD rats were selected as the control group ( $\mathrm{n}=6)$, and $18 \mathrm{SD}$ rats were selected as the diabetic group; then, according to the different periods after nerve compression of the left hind limb, they were further divided into subgroups of nerve compression for 2 weeks (DNC2W, $\mathrm{n}=6$ ), 4 weeks (DNC4W, $\mathrm{n}=6$ ) and 8 weeks (DNC8W, n=6). Meanwhile, the contralateral sciatic nerves were evaluated by SWE at 2, 4, and 8 weeks. All experimental procedures involving animals were approved by the Institutional Animal Care and Use Committee of Peking University People's Hospital (2017PHC061).

\section{Model establishment of diabetic sciatic nerve compression}

All SD rats were placed in the specific pathogen-free experimental environment for 7 days for acclimation. The rats of diabetic group were fed with a high-glucose highfat diet for 4 weeks, and then given a single intraperitoneal injection of streptozotocin (STZ) (Sigma Chemical Co., USA) $40 \mathrm{mg} / \mathrm{kg}$. Seven days after the STZ administration, rats with random blood glucose concentrations higher than $16.7 \mathrm{mmol} / \mathrm{L}$ were designated to the diabetic group (17). Before surgery, intraperitoneal induction of ketamine $(60 \mathrm{mg} / \mathrm{kg})$ was performed for anesthesia. The sciatic nerve of the left hind limb was exposed. Then, the sciatic nerve was surrounded by a silicone tube at the middle third of the sciatic nerve (18). The length of the silicone tube was 1 $\mathrm{cm}$, and the inner diameter was $1.2 \mathrm{~mm}$. A longitudinal slit was made in the silicone tube that permitted the operator to open the tube with the arms of dissecting scissors so that the tube could slide directly around the nerve with minimal trauma. The silicone tube was fixed with 6-0 nylon sutures to avoid sliding. All the surgical procedures were performed by the same manipulator to avoid interoperator influence. Also, all the surgical procedures were subjected to the principles of aseptic operation.

\section{SWE examination}

All SWE examinations were performed by using a $20 \mathrm{MHz}$ linear-array transducer (SuperSonic Imagine, France). Rats were anesthetized by intraperitoneal injection of ketamine $(60 \mathrm{mg} / \mathrm{kg})$. Before the examination, the silicone tube and inflammatory tissue surrounding the sciatic nerve were removed gently to ensure the integrity of the nerve. SD rats were lying in the lateral position, with the hind limb relaxed. The nerve was scanned in the vertical section. SWE was performed with care to avoid a compression effect of the transducer. The region of interest size was 
fixed to $0.01 \mathrm{~cm}^{2}$ in all cases, and the border of the sample frame was placed inside the nerve epineurium. The SWE of nerves was measured 3 times at the compression site to increase reproducibility, with the average value being chosen for the following analysis. All study groups were independently examined by 2 operators, who had over 5 years of experience in ultrasound examination. Operator 2 repeated elastography measurements with the same method but was blind to the results of Operator 1 .

\section{Electrophysiological studies}

Rats were anesthetized with ketamine by intraperitoneal injection $(60 \mathrm{mg} / \mathrm{kg})$. Motor nerve conduction velocity (MNCV) of the sciatic nerve was measured using a TECA Synergy electronic medical instrument (VIASYS Healthcare, USA) at 2, 4, and 8 weeks post-compression in the diabetic group and the control group. The stimulating electrode was placed on the proximal and distal sides of the compression area of the sciatic nerve (stimulation duration, $0.1 \mathrm{~ms}$; frequency, $1 \mathrm{~Hz}$; stimulus intensity, $0.12 \mathrm{~mA}$ ). The reference recording electrode was inserted into the quadriceps femoris, and the recording electrode was placed on the tibialis anterior muscle.

\section{Histological and quantitative morphometry of the sciatic nerve}

Nerve samples were evaluated via transmission electron microscopy analysis at 2, 4, and 8 weeks after compression in rats of the diabetic and control groups. The specimens of sciatic nerves were fixed in $3 \%$ glutaraldehyde in $0.1 \mathrm{M}$ phosphate buffer $(\mathrm{PB})(\mathrm{pH}, 7.4)$ at $4{ }^{\circ} \mathrm{C}$ overnight. Then, they were post-fixed in $1 \% \mathrm{OsO}_{4}$ (Sigma Chemicals Co., USA) in PB for $2 \mathrm{~h}$, dehydrated in a graded increasing series of alcohol and propylene oxide (Electron Microscopy Sciences, Hatfield, PA, USA), embedded in resin (Durcupan, ACM-Fluka, Switzerland), and polymerized at $60{ }^{\circ} \mathrm{C}$. Semithin transections $(1 \mu \mathrm{m})$ were obtained using an ultramicrotome (MT 6000-XL, RMC, Tucson, Arizona) and stained with $1 \%$ toluidine blue (Merck, Germany) in $1 \%$ sodium tetraborate (Ecibra, Brazil). Semi-thin sections were observed under a light microscope $(1,000 \times)$ (Olympus BX51, Japan) to assess the myelinated fiber density (number of fibers $/ \mathrm{mm}^{2}$ ). Next, the resin-embedded tissues were cut into ultrathin sections $(50 \mathrm{~nm})$ and double-stained with uranyl acetate and lead citrate. After dehydration with ethanol and acetone, the samples were observed under transmission electron microscopy $(2,550 \times)$ (Fei Tecnai G2 F20, USA) to assess myelin sheath thickness $(\mu \mathrm{m})$ and $\mathrm{g}$ ratio (axon diameter/fiber diameter, a measurement of the degree of myelination). All data of quantitative morphometry mentioned above were estimated according to the previous method $(19,20)$, using the measuring software of the Image Plus Pro 6.0. A single investigator blinded to the samples performed the morphometric analysis.

\section{Statistical studies}

Statistical analysis was performed using SPSS (22.0). All data were presented as the mean \pm standard deviations. The Anderson-Darling normality test was used for the evaluation of normal distribution. A comparison between groups was performed using one-way analysis of variance (ANOVA) followed by Bonferroni test or Tamhane's T2 test. Pearson's correlation analysis was used to investigate the relationship between the SWE and MNCV results. The interobserver agreement of the values of SWE was determined by the intraclass correlation coefficient (ICC).

\section{Results}

The mean values of nerve stiffness evaluated by SWE at 2,4 , and 8 weeks after nerve compression in rats of the diabetic groups shown in Table 1 and Figure 1; the stiffness of the nerve at the compression site increased markedly as did the duration time of compression $(\mathrm{P}<0.01)$. The data for the contralateral sciatic nerve of DNC2W, DNC4W, and DNC8W are also shown in Figure 1 and Table 1, and no differences were found in the comparison with the control group $(\mathrm{P}>0.05)$. There was excellent interobserver consistency of SWE. The consistency value for the elasticity was 0.978 . The fasting blood glucose concentrations of diabetic rats at 2,4 , and 8 weeks was $21.0 \pm 3.10 \mathrm{mmol} / \mathrm{L}$, $22.5 \pm 3.02 \mathrm{mmol} / \mathrm{L}$, and $22.8 \pm 3.25 \mathrm{mmol} / \mathrm{L}$ respectively, and there was no significant difference between the 3 groups $(\mathrm{P}>0.05)$.

The MNCV of CON, DNC2W, DNC4W, and $\mathrm{DNC} 8 \mathrm{~W}$ was $64.83 \pm 3.65 \mathrm{~m} / \mathrm{s}, 42.67 \pm 3.20 \mathrm{~m} / \mathrm{s}$, $36.50 \pm 3.01 \mathrm{~m} / \mathrm{s}$, and $30.83 \pm 2.31 \mathrm{~m} / \mathrm{s}$, respectively. The MNCV decreased along with the duration time of nerve compression $(\mathrm{P}<0.01$; Figure 2). The nerve stiffness depicted by SWE was negatively correlated with $\mathrm{MNCV}$ ( $\mathrm{r}=-0.926$; $\mathrm{P}<0.01)$.

Analysis of the morphometric data revealed that all compression groups showed a remarkably greater decrease 
Table 1 Data of SWE

\begin{tabular}{|c|c|c|c|c|}
\hline \multirow{2}{*}{ Operator } & \multirow{2}{*}{ Groups } & \multirow{2}{*}{$\begin{array}{c}\text { SWE }(\mathrm{m} / \mathrm{s}) \\
(\text { mean } \pm \mathrm{SD})\end{array}$} & \multicolumn{2}{|c|}{$95 \% \mathrm{Cl}$} \\
\hline & & & Lower & Upper \\
\hline \multirow[t]{7}{*}{ Operator 1} & CON & $1.77 \pm 0.08$ & 1.68 & 1.85 \\
\hline & DNC2W & $2.18 \pm 0.08^{\star \star}$ & 2.10 & 2.23 \\
\hline & DNC4W & $2.50 \pm 0.06^{\star \star}$ & 2.43 & 2.57 \\
\hline & DNC8W & $2.73 \pm 0.10^{\star \star}$ & 2.62 & 2.84 \\
\hline & DM2W & $1.70 \pm 0.09$ & 1.61 & 1.79 \\
\hline & DM4W & $1.78 \pm 0.08$ & 1.70 & 1.86 \\
\hline & DM8W & $1.80 \pm 0.09$ & 1.71 & 1.89 \\
\hline \multirow[t]{7}{*}{ Operator 2} & CON & $1.78 \pm 0.06$ & 1.70 & 1.84 \\
\hline & DNC2W & $2.15 \pm 0.09^{\star \star}$ & 2.06 & 2.25 \\
\hline & DNC4W & $2.48 \pm 0.07^{\star \star}$ & 2.42 & 2.56 \\
\hline & DNC8W & $2.69 \pm 0.09^{\star \star}$ & 2.61 & 2.79 \\
\hline & DM2W & $1.71 \pm 0.08$ & 1.64 & 1.79 \\
\hline & DM4W & $1.80 \pm 0.06$ & 1.73 & 1.87 \\
\hline & DM8W & $1.80 \pm 0.09$ & 1.71 & 1.90 \\
\hline
\end{tabular}

SWE, shear wave elastic; CON, control group; DNC2W, sciatic nerve after 2-week compression in the diabetic rats; DNC4W, sciatic nerve after 4-week compression in the diabetic rats; DNC8W, sciatic nerve after 8-week compression in the diabetic rats. DM2W, sciatic nerve of diabetic rats at 2-week; DM4W, sciatic nerve of diabetic rats at 4-week; DM8W, sciatic nerve of diabetic rats at 8 -week. ${ }^{* *}, \mathrm{P}<0.01$ when compared across groups.

in the density of the myelinated fibers than the control group $\left(12,503 \pm 1,005\right.$ fibers $\left./ \mathrm{mm}^{2} ; \mathrm{P}<0.01\right)$. There was also a significant decrease in the density of the myelinated fibers as the duration time of nerve compression increased (DNC2W, $8,554 \pm 903$ fibers $/ \mathrm{mm}^{2}$; DNC4W, 6,753 \pm 407 fibers $/ \mathrm{mm}^{2}$, DNC8W, $5,118 \pm 847$ fibers $/ \mathrm{mm}^{2} ; \mathrm{P}<0.01$ ) (Figure 3). By week 4 , the axons of the sciatic nerve were obviously atrophic. A considerable number of demyelination changes occurred. Even some myelinated fibers appeared with Wallerian degeneration (Figure 4).

The average axon diameter in the DNC4W group $(4.02 \pm 1.11 \mu \mathrm{m})$ and DNC8W group $(3.81 \pm 1.05 \mu \mathrm{m})$ was smaller than that of the control group $(5.09 \pm 1.4 \mu \mathrm{m})$ and DNC2W group $(4.50 \pm 0.84 \mu \mathrm{m})(\mathrm{P}<0.05)$. The average myelin sheath thickness of the DNC4W group $(0.85 \pm 0.18 \mu \mathrm{m}$; $\mathrm{P}<0.05)$ and $\mathrm{DNC} 8 \mathrm{~W}$ group $(0.77 \pm 0.20 \mu \mathrm{m} ; \mathrm{P}<0.05)$ was smaller than that of the control group $(1.19 \pm 0.29 \mu \mathrm{m}$; $\mathrm{P}<0.05)$ and $\mathrm{DNC} 2 \mathrm{~W}$ group $(1.1 \pm 0.18 \mu \mathrm{m} ; \mathrm{P}<0.05)$. The results of $\mathrm{g}$ ratio showed higher value in the DNC4W group $(0.69 \pm 0.05)$ and $\mathrm{DNC} 8 \mathrm{~W}$ group $(0.73 \pm 0.05)$ than that of the control group $(0.62 \pm 0.04)$ and $\mathrm{DNC} 2 \mathrm{~W}$ group $(0.64 \pm 0.03)(\mathrm{P}<0.05)$. No differences in average axon diameter, myelin sheath thickness, and $g$ ratio were found between the DNC2W group and control group $(\mathrm{P}>0.05)$ (Figure 5).

\section{Discussion}

The pathogenesis of diabetic neuropathy is complex. Hyperglycemia leads to an excess of intramitochondrial reactive oxygen species, inflammatory reactions, and edema formation in peripheral nerves (21). The double crush hypothesis states that a diabetic nerve is more susceptible to compression than a nondiabetic nerve (7). Another study has reported that chronic nerve compression could accelerate the progression of diabetic neuropathy in the rat model (22). Therefore, diabetic nerve entrapment is a complicated process in which 2 factors of diabetic neuropathy and nerve entrapment interact with each other. A simple diabetic neuropathy model or compression model is challenging to use to explain this process. Meanwhile, an earlier study reported that there was no detectable structural abnormalities or early functional abnormalities in the peripheral nerves of the STZ-induced diabetic rats (23). Therefore, in this experiment, the Dellon model was used instead of waiting for the diabetic rats to develop peripheral neuropathy because banding the sciatic nerve with a silicone tube in STZ-induced diabetic rats promotes progression of diabetic nerve entrapment $(18,24)$.

SWE has been applied for evaluation of CTS (25) and ulnar tunnel syndrome (26), presenting a higher stiffness than healthy nerve tissue. Also, SWE was speculated to be a potential sonographic method for diagnosing diabetic neuropathy, presenting an increase of nerve stiffness, as depicted by SWE (27). In the early period of DM, the edema of the epineurium and perineurium caused by metabolic disorders of DM increases the intra-neural pressure, making the nerve stiffer $(28,29)$. Then, with more extended periods of compression, there are alterations in connective tissue layers as epineural and perineural fibrosis occurs. Nerve fiber pathology develops as "neural scar" forms secondary to fibroblast proliferation (30). As a result, we assumed that SWE could quantitatively evaluate the nerve stiffness along with the duration of nerve compression in diabetic rats. The results confirmed this, as there was higher stiffness in the diabetic nerve compression 

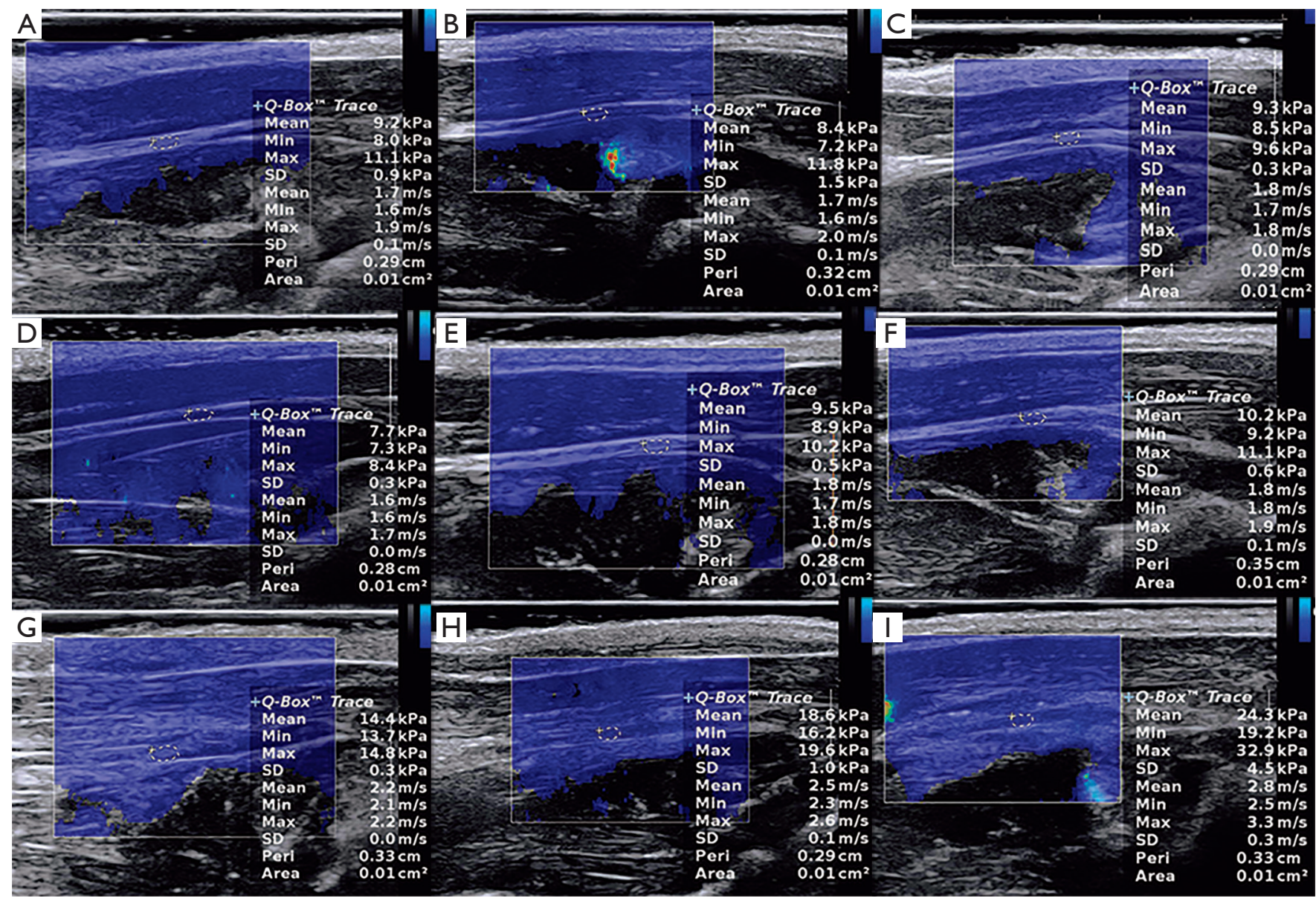

Figure 1 SWE findings of the sciatic nerve compression in diabetic rats and controls. (A,B,C) The sciatic nerve of normal rats at 2, 4, and 8 weeks. (D,E,F) The sciatic nerve of the diabetic rats at 2, 4, and 8 weeks. (G,H,I) The sciatic nerve after compression 2, 4, and 8 weeks in the diabetic rats. SWE, shear wave elastography.

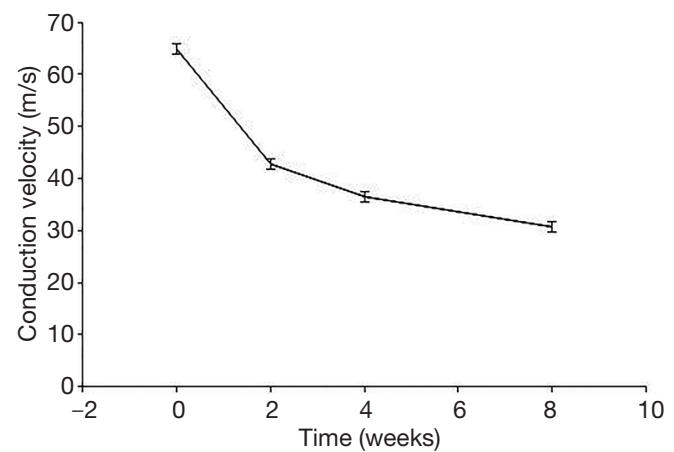

Figure 2 Alterations in motor nerve conduction velocity after chronic compression in diabetic rats. At each time point, the mean values with their standard deviations are shown in the graph. groups than the control group. Also, the nerve stiffness increased with the increase in duration of compression. The myelinated fiber density and MNCV were significantly decreased after 2 weeks of nerve compression, which is in line with a previous report indicating that even a short period of compression is capable of inducing a severe effect on the nerve tissue and the nerve morphology (31). At the same time, the nerve stiffness depicted by SWE increased after nerve a compression period of just 2 weeks, demonstrating that SWE can predict diabetic nerve entrapment in the initial period.

It is well established that diabetic neuropathy is characterized by both myelinated and unmyelinated nerve 

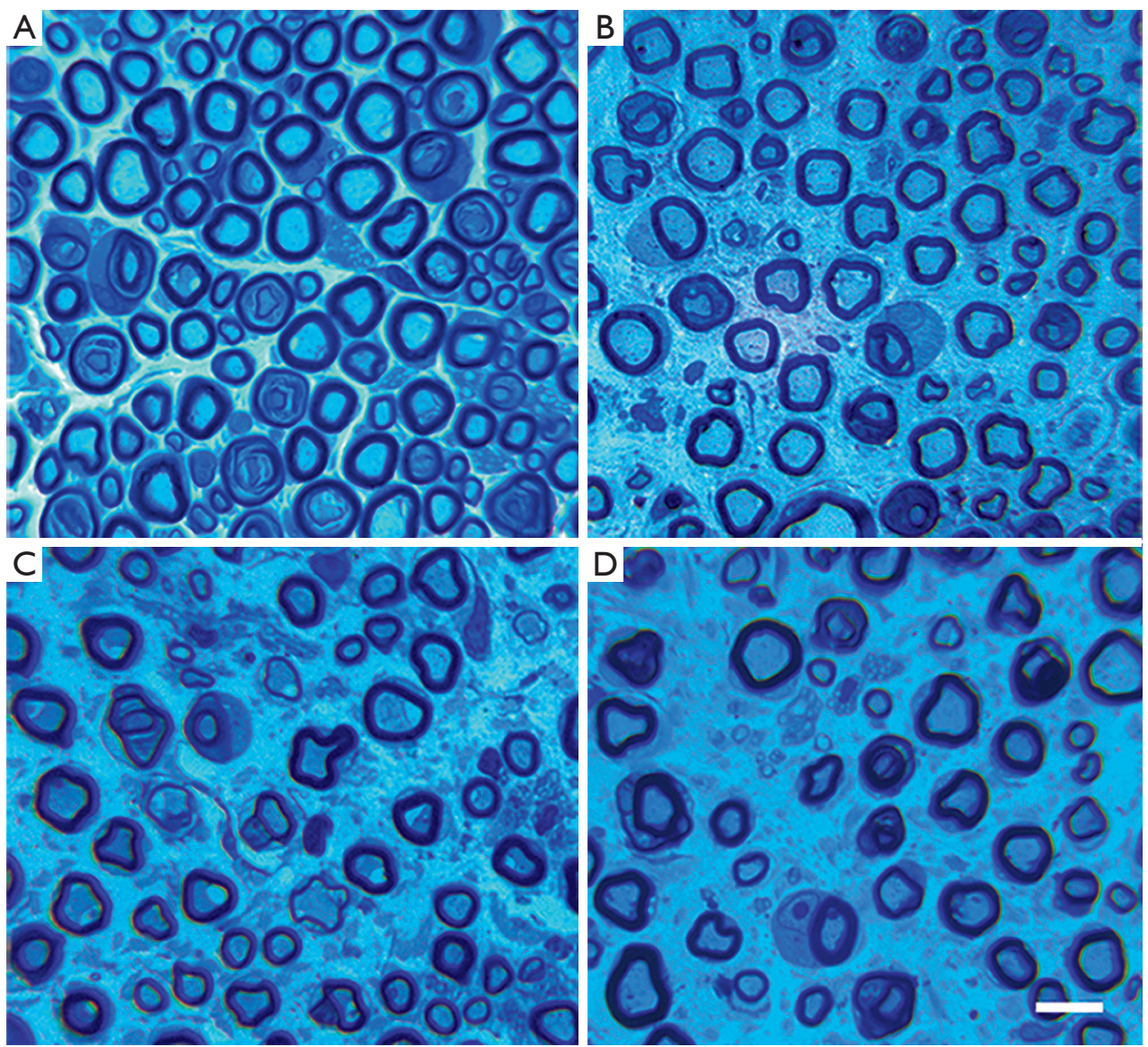

Figure 3 Toluidine blue-stained semithin sections $(1 \mu \mathrm{m})$ obtained from the sciatic nerve of all groups. (A) The control group (CON). (B) Sciatic nerve after 2-week compression in the diabetic rats (DNC2W). (C) Sciatic nerve after compression 4-week compression in the diabetic rats $(\mathrm{DNC} 4 \mathrm{~W})$. (D) Sciatic nerve after 8 -week compression in the diabetic rats (DNC8W) (magnification: $\times 1,000$; scale bar 10 $\mu$ m).
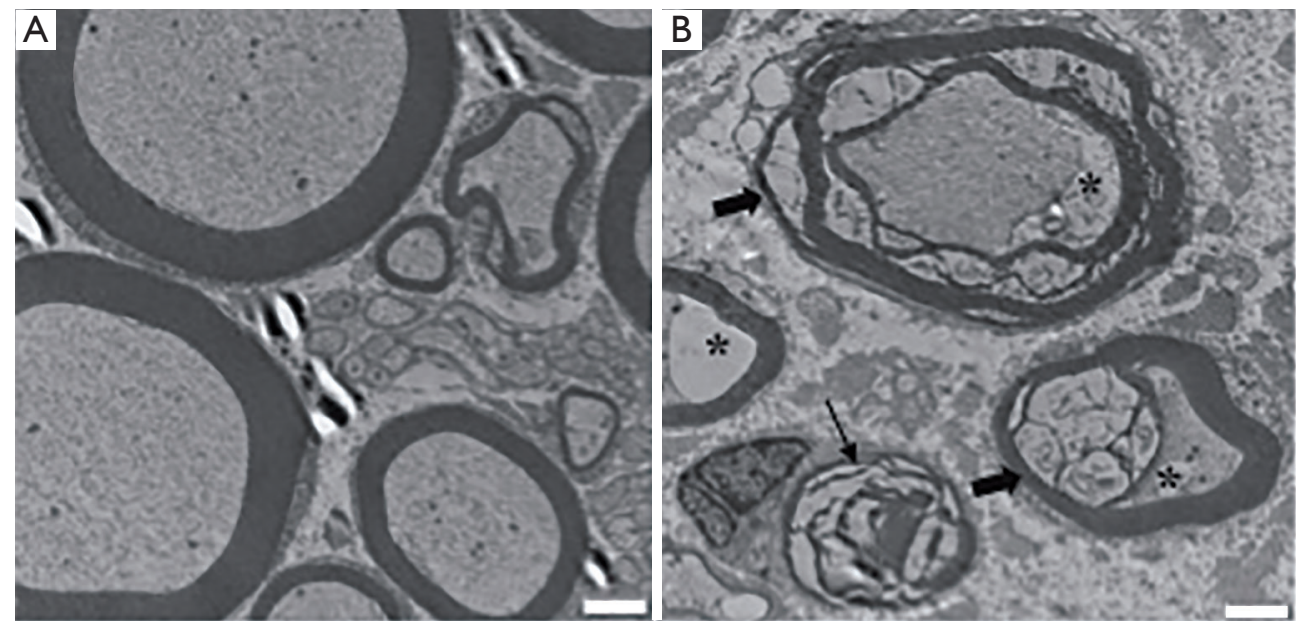

Figure 4 Transmission electron microscopy of the sciatic nerve. (A) Normal sciatic nerve. (B) Sciatic nerve at 4-week compression in diabetic rats. *, atrophy axon; thick arrow, demyelination; thin arrow, Wallerian degeneration (magnification: $\times 4,200$; scale bar $2 \mu \mathrm{m}$ ). 

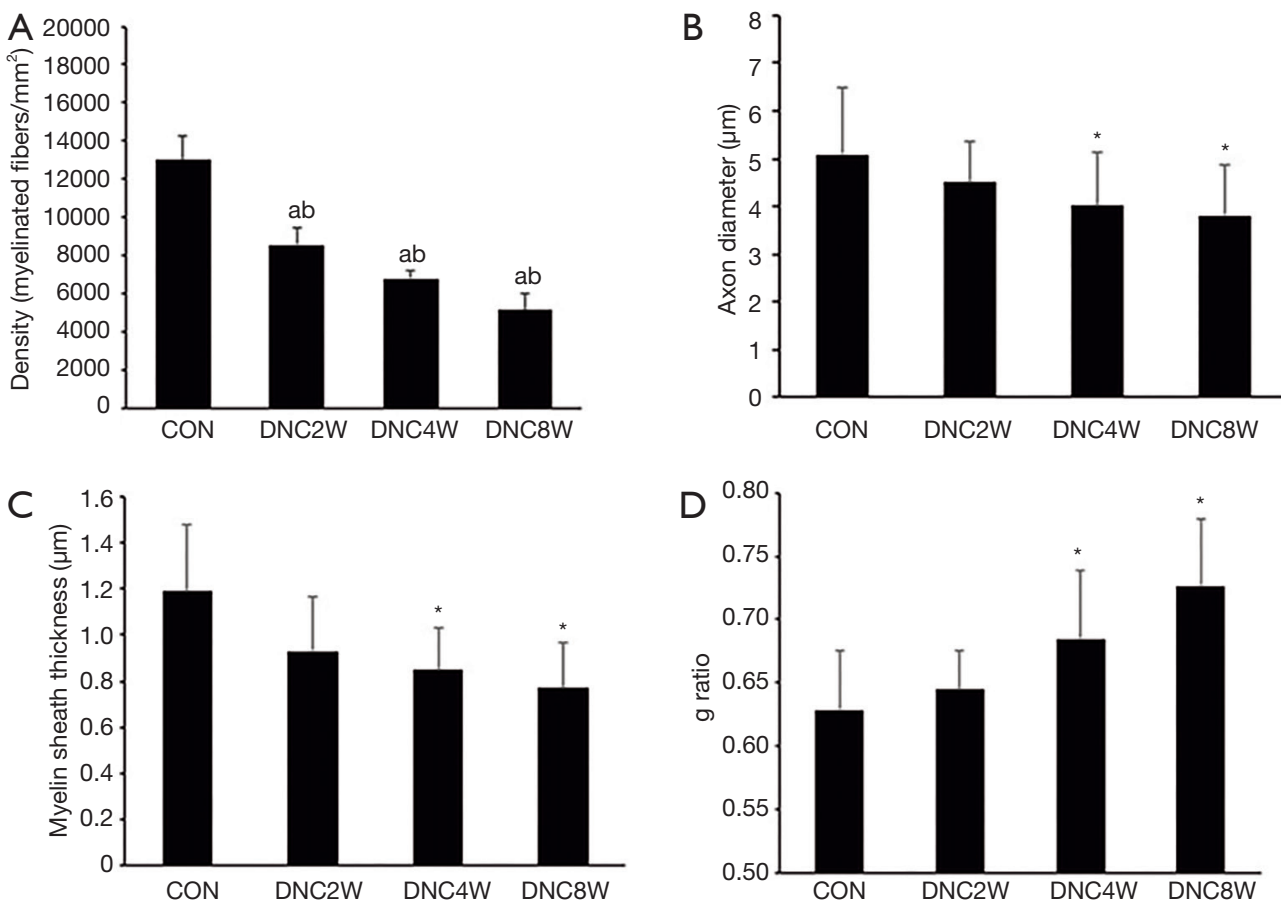

Figure 5 Morphometric parameters of the sciatic nerve fibers. All groups of sciatic nerve morphometric parameters are shown as density of myelinated fibers (A), axon diameter (B), myelin sheath thickness (C), and g ratio (D). *, corresponds to $\mathrm{P}<0.05$ when compared to CON group; ' , corresponds to $\mathrm{P}<0.05$ when compared to $\mathrm{CON}$ group; ${ }^{\mathrm{b}}$, corresponds to $\mathrm{P}<0.05$ when compared across groups. CON, control; DNC2W, diabetic nerve after 2-week compression; DNC4W, diabetic nerve after 4-week compression; DNC8W, diabetic nerve after 8-week compression.

fiber degeneration and regeneration, and mainly involves myelinated fibers (32). One of the features of diabetic neuropathy is the decline of the density of the myelinated fibers (33). Also, chronic nerve compression induces alterations in myelin structure that reflect demyelination and remyelination. Histological evaluations have revealed that axons at the periphery of the nerve fascicle lose their myelin after 4 weeks of sustained compression (30). Previous research has shown that changes in the axonal diameter may be a potential trigger for Schwann cell proliferation and alterations in myelin thickness (34). Our results showed that average axon diameter, myelin sheath thickness, and the g ratio were significantly different in the DNC4W group compared to the control group, whereas there were no significant differences between the DNC2W group and control group. These findings are consistent with earlier studies. However, more obvious alterations of the axon and myelin in the nerve require a longer period of sustained compression (35). Given this, there were no differences found in average axon diameter, myelin sheath thickness, and $g$ ratio between the DNC4W and DNC8W group. However, our study showed that the density of the myelinated fibers gradually decreased with increase in the duration of nerve compression of the diabetic nerve. This, according to a previous study, could also suggest the progression of neuropathic severity by myelinated fiber progressive loss (36), and was also demonstrated by $\mathrm{MNCV}$ in terms of neural function.

Electrophysiological examination is still the gold standard for evaluating the peripheral nerve function. Still, many studies have shown that the higher stiffness depicted by SWE can predict the neuropathy in a diabetic patient in a noninvasive manner; however, whether the higher stiffness depicted by SWE can predict the severity of diabetic nerve entrapment is unknown. Therefore, further investigations that can qualitatively evaluate diabetic nerve entrapment by SWE in predicting the pathological and functional changes of nerve lesions should be done in the future. Our present work can be used as a preliminary experimental substructure to determine the feasibility of quantitative evaluation to reflect the severity of nerve lesions by SWE in diabetic nerve entrapment. 
There are several limitations to our study. Firstly, diabetic nerve neuropathy mostly happens in the middle or late period of DM. The nerve stiffness after a longer period of nerve compression in DM should be investigated in a future study. Secondly, our study evaluated the nerve stiffness without the effect of persistent pressure of surrounding silicone tube. However, in clinical conditions, the value of SWE can be affected by the pressure from the surrounding tissues, for example, CTS. This influencing factor should be explored in the future. Thirdly, this study only investigated the nerve stiffness affected by different compression times, and the effect of different pressure intensities on the nerve should be further explored.

In conclusion, the SWE of nerves in diabetic rats with nerve entrapment was stiffer than the control group. Meanwhile, an increase in SWE value, along with a longer duration of nerve compression, could reflect the severity of diabetic nerve entrapment. These results were confirmed by histological morphometry of myelinated fiber and electrophysiology. Therefore, SWE may be used as a noninvasive and effective method to quantitatively evaluate the severity of diabetic nerve entrapment.

\section{Acknowledgments}

We are grateful to Dr. Yusong Yuan, who has contributed to works for nerve compression model and electrophysiological examination.

Funding: This research was supported by the Youth Project of National Natural Science Foundation of China (81701712).

\section{Footnote}

Reporting Checklist: The authors have completed the ARRIVE reporting checklist. Available at http://dx.doi. org/10.21037/atm-19-4534

Data Sharing Statement: Available at http://dx.doi. org/10.21037/atm-19-4534

Peer Review File: Available at http://dx.doi.org/10.21037/ atm-19-4534

Conflicts of Interest: All authors have completed the ICMJE uniform disclosure form (available at http://dx.doi. org/10.21037/atm-19-4534). The authors have no conflicts of interest to declare.

Ethical Statement: The authors are accountable for all aspects of the work in ensuring that questions related to the accuracy or integrity of any part of the work are appropriately investigated and resolved. All experimental procedures involving animals were approved by the Institutional Animal Care and Use Committee of Peking University People's Hospital (2017PHC061).

Open Access Statement: This is an Open Access article distributed in accordance with the Creative Commons Attribution-NonCommercial-NoDerivs 4.0 International License (CC BY-NC-ND 4.0), which permits the noncommercial replication and distribution of the article with the strict proviso that no changes or edits are made and the original work is properly cited (including links to both the formal publication through the relevant DOI and the license). See: https://creativecommons.org/licenses/by-nc-nd/4.0/.

\section{References}

1. Edwards JL, Vincent AM, Cheng HT, et al. Diabetic neuropathy: mechanisms to management. Pharmacol Ther 2008;120:1-34.

2. Vinik AI, Park TS, Stansberry KB, et al. Diabetic neuropathies. Diabetologia 2000;43:957-73.

3. Tesfaye S, Boulton AJ, Dickenson AH. Mechanisms and management of diabetic painful distal symmetrical polyneuropathy. Diabetes Care 2013;36:2456-65.

4. Karpitskaya Y, Novak CB, Mackinnon SE. Prevalence of smoking, obesity, diabetes mellitus, and thyroid disease in patients with carpal tunnel syndrome. Ann Plast Surg 2002;48:269-73.

5. Gamstedt A, Holm-Glad J, Ohlson CG, et al. Hand abnormalities are strongly associated with the duration of diabetes mellitus. J Intern Med 1993;234:189-93.

6. Dyck PJ, Kratz KM, Karnes JL, et al. The prevalence by staged severity of various types of diabetic neuropathy, retinopathy, and nephropathy in a population-based cohort: the Rochester Diabetic Neuropathy Study. Neurology 1993;43:817-24.

7. Upton AR, McComas AJ. The double crush in nerve entrapment syndromes. Lancet 1973;2:359-62.

8. Dellon AL. Treatment of symptomatic diabetic neuropathy by surgical decompression of multiple peripheral nerves. Plast Reconstr Surg 1992;89:689-97; discussion 698-9. 
9. Aszmann OC, Kress KM, Dellon AL. Results of decompression of peripheral nerves in diabetics: a prospective, blinded study. Plast Reconstr Surg 2000;106:816-22.

10. Makepeace A, Davis WA, Bruce DG, et al. Incidence and determinants of carpal tunnel decompression surgery in type 2 diabetes: the Fremantle Diabetes Study. Diabetes Care 2008;31:498-500.

11. Kakrani AL, Gokhale VS, Vohra KV, et al. Clinical and nerve conduction study correlation in patients of diabetic neuropathy. J Assoc Physicians India 2014;62:24-7.

12. Nazish S, Zafar A, Shahid R, et al. Electrophysiologic severity of carpal tunnel syndrome in diabetic patients of the Saudi population. Neurosciences (Riyadh) 2019;24:22-8.

13. Chen S, Urban MW, Pislaru C, et al. Shearwave dispersion ultrasound vibrometry (SDUV) for measuring tissue elasticity and viscosity. IEEE Trans Ultrason Ferroelectr Freq Control 2009;56:55-62.

14. Hobson-Webb LD, Massey JM, Juel VC. Nerve ultrasound in diabetic polyneuropathy: correlation with clinical characteristics and electrodiagnostic testing. Muscle Nerve 2013;47:379-84.

15. He Y, Xiang X, Zhu BH, et al. Shear wave elastography evaluation of the median and tibial nerve in diabetic peripheral neuropathy. Quant Imaging Med Surg 2019;9:273-82.

16. Moran L, Royuela A, de Vargas AP, et al. Carpal Tunnel Syndrome: Diagnostic Usefulness of Ultrasound Measurement of the Median Nerve Area and Quantitative Elastographic Measurement of the Median Nerve Stiffness. J Ultrasound Med 2020;39:331-9.

17. Junod A, Lambert AE, Stauffacher W, et al. Diabetogenic action of streptozotocin: relationship of dose to metabolic response. J Clin Invest 1969;48:2129-39.

18. Dellon AL, Mackinnon SE. Chronic nerve compression model for the double crush hypothesis. Ann Plast Surg 1991;26:259-64.

19. Ilha J, Araujo RT, Malysz T, et al. Endurance and resistance exercise training programs elicit specific effects on sciatic nerve regeneration after experimental traumatic lesion in rats. Neurorehabil Neural Repair 2008;22:355-66.

20. de Medinaceli L. Interpreting nerve morphometry data after experimental traumatic lesions. J Neurosci Methods 1995;58:29-37.

21. Wang PH, Yang CC, Su WR, et al. Effects of decompression on behavioral, electrophysiologic, and histomorphologic recovery in a chronic sciatic nerve compression model of streptozotocin-induced diabetic rats. J Pain Res 2017;10:643-52.

22. Tu Y, Chen Z, Hu J, et al. Chronic Nerve Compression Accelerates the Progression of Diabetic Peripheral Neuropathy in a Rat Model: A Study of Gene Expression Profiling. J Reconstr Microsurg 2018;34:537-48.

23. Walker D, Carrington A, Cannan SA, et al. Structural abnormalities do not explain the early functional abnormalities in the peripheral nerves of the streptozotocin diabetic rat. J Anat 1999;195:419-27.

24. Dellon AL, Mackinnon SE, Seiler WAt. Susceptibility of the diabetic nerve to chronic compression. Ann Plast Surg 1988;20:117-9.

25. Kantarci F, Ustabasioglu FE, Delil S, et al. Median nerve stiffness measurement by shear wave elastography: a potential sonographic method in the diagnosis of carpal tunnel syndrome. Eur Radiol 2014;24:434-40.

26. Paluch L, Noszczyk BH, Walecki J, et al. Shear-wave elastography in the diagnosis of ulnar tunnel syndrome. J Plast Reconstr Aesthet Surg 2018;71:1593-9.

27. Dikici AS, Ustabasioglu FE, Delil S, et al. Evaluation of the Tibial Nerve with ShearWave Elastography: A Potential Sonographic Method for the Diagnosis of Diabetic Peripheral Neuropathy. Radiology 2017;282:494-501.

28. Clements RS Jr. Diabetic neuropathy--new concepts of its etiology. Diabetes 1979;28:604-11.

29. Tuck RR, Schmelzer JD, Low PA. Endoneurial blood flow and oxygen tension in the sciatic nerves of rats with experimental diabetic neuropathy. Brain 1984;107:935 50.

30. O'Brien JP, Mackinnon SE, MacLean AR, et al. A model of chronic nerve compression in the rat. Ann Plast Surg 1987;19:430-5.

31. Pettersson LM, Danielsen N, Dahlin LB. Altered behavioural responses and functional recovery in rats following sciatic nerve compression and early vs late decompression. J Plast Surg Hand Surg 2016;50:321-30.

32. Brussee V, Guo G, Dong Y, et al. Distal degenerative sensory neuropathy in a long-term type 2 diabetes rat model. Diabetes 2008;57:1664-73.

33. Malik RA, Veves A, Walker D, et al. Sural nerve fibre pathology in diabetic patients with mild neuropathy: relationship to pain, quantitative sensory testing and peripheral nerve electrophysiology. Acta Neuropathol 2001;101:367-74.

34. Griffin JW, Drucker N, Gold BG, et al. Schwann 
Page 10 of 10

cell proliferation and migration during paranodal demyelination. J Neurosci 1987;7:682-99.

35. Gupta R, Rowshan K, Chao T, et al. Chronic nerve compression induces local demyelination and
Li et al. Evaluation of DNC by elastography

remyelination in a rat model of carpal tunnel syndrome. Exp Neurol 2004;187:500-8.

36. Malik RA. The pathology of human diabetic neuropathy. Diabetes 1997;46 Suppl 2:S50-3.

Cite this article as: Li D, Zhu J, Liu F, Li B, Liu F, Li W. A quantitative evaluation of sciatic nerve stiffness after compression by shear wave elastography in diabetic rats. Ann Transl Med 2020;8(11):682. doi: 10.21037/atm-19-4534 